ROMAN GUMZEJ, Ph.D. ${ }^{1}$

(Corresponding author)

E-mail: roman.gumzej@um.si

BOJAN ROSI, Ph.D. ${ }^{1}$

E-mail: bojan.rosi@um.si

${ }^{1}$ University of Maribor, Faculty of Logistics

Mariborska cesta 7, 3000 Celje, Slovenia
Transport and Sustainable Development

Original Scientific Paper

Submitted: 18 Apr. 2017

Accepted: 21 Nov. 2017

\title{
AN AGENT-BASED SIMULATION OF A QOS-ORIENTED SUPPLY CHAIN
}

\begin{abstract}
With adaptive customer-orientation the efficiency of supply chain management is improved substantially. By the introduction of service quality-based decision-making into supply chain management the quality of service (QoS) within supply chains is expected to improve autonomously and continuously up- and downstream. In the paper the main characteristics of quality of service oriented supply chain management are outlined. The quality of service criterion, introduced into the adaptive supply chain model, provides market regulators and managements with the needed information and feedback to their increasingly informed decisions. By an experiment comprising several typical scenarios on our agent-based simulation model it was possible to empirically verify the expected impact of quality of service-based reasoning on generic adaptive supply chains.
\end{abstract}

\section{KEY WORDS}

supply chain; adaptive; quality of service; management; agent-based simulation;

\section{INTRODUCTION}

A supply chain (SC) can be seen as a complex adaptive system of interrelated and interdependent elements, which collaborate in executing different activities in order to achieve some preliminary set objectives. According to [1], a complex adaptive system is a system that evolves through time into a coherent whole that adjusts and self-organizes itself without any individual entity intentionally controlling or supervising it. Christopher [2] states that "the supply chain is a network of organizations working together in different processes and activities in order to bring products and services to the market, with the purpose of satisfying customer's demands".

Decision-makers in supply chains are often faced with strategic decision-making challenges with only partial information on the system structure and/or system operation. Hence, the adopted decisions may have a negative impact on overall supply chain performance. These situations should be avoided and can be prevented by utilizing decision support tools (DST). DSTs enable business and/or organizational decision-making based on rapidly changing data not known in advance. Applying the holistic modelling approach to capture the extended supply chain at a strategic level of an enterprise within a DST may be the solution to our decision-making problem [3].

As a network of organizations, the SC is obliged to have clearly defined objectives. The main objective of the supply chain is the maximization of total profits derived across different echelons of the supply chain. The second most important objective, however, is the maximization of customer satisfaction, expressed by the service level [4], also referred to as quality of service (QoS). While the majority of DST-based approaches deal with the first objective, the fulfilment of the second objective, in our opinion, is interrelated with it and as such should be considered in conjunction [5]. The set goals can only be attained by adequate supply chain configuration and proper use of management tools. The latter are provided by supply chain management (SCM), being the process of planning, implementing and controlling the operations of the supply chain in an efficient way. SCM spans all movements and storage of raw materials, work-in-process inventory, and finished goods from the point of origin to the point of consumption [6].

SCM addresses a wide range of problems, which may be divided into three categories [7]:

- supply chain infrastructure (network) design,

- supply chain analysis and policy formulation,

- supply chain planning and scheduling.

Within the process of modelling and solving the indicated problems, managers have to make decisions on different hierarchical levels. These decisions can be classified as strategic, tactical and operational, depending on their effects on the overall supply chain. Due to interdependence among the three levels, SCM remains incapable of satisfactorily addressing many practical real-world problems at a strategic level. Let alone that these levels are difficult to tackle at any individual level, due to inter-dependencies among entities and their autonomous behaviour they are even more difficult to address. Hence, the majority of modelling approaches in DST provide invalid results [8]. 
For obtaining adequate solutions at the strategic level, decision-makers need comprehensive models to guide them in the decision-making process.

System dynamics (SD), being a simulation-based modelling approach, which underpins DST and holistic modelling $[8,9]$, is widely used in logistics and supply chain management. On the other hand, SD-based models are mainly applicable in situations where the type of flow elements can be unified (e.g. on transaction level) and the type and behaviour of their manipulation entities (supply chain nodes) do not change over time, and as such impose no further restrictions to the simulation $[10,11]$. In case the behaviour of the modelled system depends on decisions and interactions among heterogeneous entities, the agent-based simulation (ABS), an over-set of SD, approach to modelling and simulation of such systems should be used [12, 13].

Here, an ABS-based model of a multi-echelon supply chain, which may be used to analyse and fine tune the behaviour of supply chain nodes, is presented. The layout of this paper is as follows. First, the SCM model and its integration into an ABS model is presented. Next, the ABS model for a generic supply chain is presented with the demonstration of the node behaviours according to the selected strategy. Finally, the results of different simulation scenarios are analysed and a conclusion on the outcomes is drawn.

\section{QOS-ORIENTED SCM}

Our supply chain evaluation method is based on the adaptable (customer-led) supply chain model and considers the supply chain as a composition of partners, fulfilling the customer-supplier relationship [5]. QoS-probes are inserted on every link among any two elements fulfilling this relation. Hereby, service quality is observed between producers and their suppliers of materials and components, producers and retailers of their products, as well as customers and retailers. Any input transaction on a link represents a response to a call for proposals and has two properties - price and QoS value - that are considered by a customer when deciding on the acceptance or refusal of a supplier's proposal. Usually, the decision is made solely based on price, where the lowest price is considered the best offer. However, due to often questionable QoS of such offers, this decision is not always the best one. Hence, customers usually rely on a (set of) trusted supplier(s) with whom they establish contract relationships that are considered a priority above the price criterion. This criterion is QoS-related and represents a level of trust between a customer and their supplier.

The QoS value is calculated based on the given model to determine whether an entity should establish or disrupt the contract relationships with its suppliers. Market regulators intervene with inspections throughout supply chains in order to assure an adequate level of quality of products and/or services offered. Products or services of lower quality are deprecated, since they result in lowering partner's wealth and usually also result in the loss of trust. Hence, the tendency is to build trusted relations among supply chain partners, usually resulting in contract relationships. We may conclude that the market partly regulates itself; for the other part, however, market regulators are necessary to restrain bad business practices.

Prior to any transaction between supply chain partners the corresponding probe is evaluated based on the provided values for the individual partner's QoS and price. With each transaction the partner's QoS value is updated and stored for later reference. The gathered data are used for monitoring and analysis of supply chain excellence represented by the mean value of all partner's QoS values. In order for this benchmark to be meaningful, all the measured values must lie within a predefined threshold. Hence, all QoS indicators are normalized and joined in a single value [5], representing QoS of any distinct node in the supply chain. It shall be used to enable quick decisions and comparison among supply chains by their partners. By constructing and embedding a QoS-based agent based simulation model in a DST system, closed loop analysis and performing "what-if" scenarios are enabled to assist the decision-makers at supply chain nodes with their informed SCM decisions.

\section{QOS-ORIENTED SC ABS MODEL}

Since business relations are essentially about obtaining and maintaining supply chain partner's wealth, in this research the effect of good and bad business practices is reflected by positive and negative financial stimuli. Market regulators in the form of inspectors are introduced into the model to monitor the state of trustfulness (QoS) of supply chain partners. An agentbased simulation model has been devised to monitor the overall QoS within a supply chain, based on the given initial number of producers, retailers and market regulators as well as the parameters that represent the market regulation policy. By different scenarios the most efficient distribution of contractual and non-contractual partners as well as market regulation policy can be discovered. Since the geographical distribution of the producers and retailers in space is unknown, it is assumed to be random. Hence, also their positioning does not affect their pricing policies in any way.

\subsection{Model overview}

The framework of the model consists of three agent types: (1) producer agents, (2) retailer agents, (3) regulator agents. 
There are $n$ producers in a product production base, and each producer produces $s$ units of a product. At a wholesale market, there are $m$ retailers that deal with the producers. There are $x$ regulator agents who perform inspections on producers and retailers. The behaviours of different types of agents are further described below.

Considering the trust-related credence attributes between customers and suppliers, there is a problem of information asymmetry, since they cannot be directly observed and are difficult to measure. The producers can be trusted or distrusted and it depends on their decision regarding their quality of service (QoS). In our supply chain model, non-contractual retailers make transactions with non-contractual producers stochastically. Contractual retailers make transactions with contractual producers building fixed transaction relationships. Contractual modes are trust-related and can be switched under certain circumstances. Producers' and retailers' trustfulness is monitored by the reg ulator agents who issue fines in case of inadequate business practices are detected.

\subsection{Regulator-agent}

In the model, the regulator agents are several market regulator's departments which supervise different parts of the supply chain. Here, for simplicity reasons, two types of regulator agents are assumed, one for the producers and another for retailers, respectively. The goal of the market regulators is to improve the service quality within the supply chain by means of sampling inspection and punishment under certain conditions. The goal of the retailers is to maintain contract relationships with trusted producers only. There are different inspecting ratios for producers $\Theta_{1}$ and retailers $\Theta_{2}$. $\alpha$ is the frequency of product inspections. The fine on producers is $f_{1}$, and the fine on retailers is $f_{2}$. They are understood per product shipped or product sold.

\subsection{Producer-agent}

A producer produces a number of products and sells them to one of the retailers. The producer's goal is to maximize its profit. The attributes of a producer are producer's type (contractual or non-contractual), trustfulness, wealth, and transformational threshold.

The producer's trustfulness level (QoS) indicates its ability to resist the shock of benefit produced by the gap between expected returns of trusted and distrusted production. The decision on trustfulness is built into the model as a function of producers' experience. With every transaction the producer gains experience with regard to its benefit or loss, in case that during inspection its inadequate business practice was detected. The following formulas show quality of service updating as a function of producer's experience under different situations:
$\mathrm{QoS}_{t+1}=\left(1-d^{+}\right) \cdot \mathrm{QoS}_{t}+d^{+} \cdot \mathrm{QoS}_{\min }$

$$
\mathrm{QoS}_{t+1}=\left(1-d^{-}\right) \cdot \mathrm{QoS}_{t}+\mathrm{QoS}_{\min }
$$

where $\mathrm{QoS}_{t}$ represents the value of QoS after $t$ transactions. A value of QoS close to 0 represents the fact that the producer is prone to cheating. The QoS value closer to 1 represents the producer's tendency to be trustworthy. Parameters $d^{+}$and $d^{-}$where $\left(0<d^{+}<1,0<d^{-}<1\right.$, $d^{-}>d^{+}$) are impact factors of positive and negative experience, respectively. The parameter $Q o S_{\min }$ represents a minimal level of trust, where $\left(0<Q \circ S_{\min }<1\right)$ and is initially set to 0.1 . If the producer is not found cheating, its new QoS value is calculated according to (1); otherwise the new value is calculated according to (2). The updating of the producer's experience and hence the decision on the investment into a trustworthy production is simplified. It is based on the assumption that the most recent experience has the stronger influence, representing the short memory effect. It is also influenced by the fact that a negative experience has a stronger influence than a positive experience, representing the endowment effect.

The producer sells its products to the retailers after production, and makes a profit that equals the total revenue minus total cost, where the revenue is the sales revenue from the market, and the cost includes the production cost and a fine, if producer's distrustfulness is detected. Furthermore, the profit changes the producer's wealth. We assume a uniform transaction price $\left(p_{1}\right)$ produced with the realisation of the transaction between a producer and a retailer:

$p_{1}(t)=\lambda c s+(1-\lambda) c l+\varepsilon(t), \varepsilon(t) \sim N\left(\mu, \sigma^{2}\right)$

where cs is the cost of trusted production for a non-contract producer, $\mathrm{Cl}$ is the cost of distrusted production and $\varepsilon(t)$ is a random real number following normal distribution, which reflects fluctuations on the market, and $\lambda$ is a weight set in the interval $(0,1)$, representing market flexibility.

The producer's decision on trustworthy production depends mainly on three parameters: economic benefits comparison, random factors and current level of trustfulness. The following formula expresses this production decision:

$\lambda k_{i}+(1-\lambda) p>Q_{o S}$

If this inequality is satisfied, the producer ships a certain number of products in an inadequate way, hereby reducing its QoS by $\mathrm{QoS}_{\min }$. Otherwise, the producer ships a certain number of products in an adequate way, hereby increasing its QoS by $Q_{0 S}$ min. Here $\rho$ is a random number $(0<\rho<1) ; k_{i}$ is a normalized value, which is given based on the gap between the expected returns by trusted production, which is chosen in two ways based on the fact whether one is a non-contractual producer (5) or contractual producer (6): 


$$
\begin{aligned}
& k_{1}=\frac{\frac{c s-c l-f_{1}}{n_{1}}}{c s-c l} \\
& k_{2}=\frac{c^{\prime} s-c l-\frac{f_{1} \Theta_{1}}{n_{1}}-\frac{f_{3} \alpha \Theta_{2}}{m_{1} b s}+\frac{\left(f_{1}+f_{3}\right) \alpha \Theta_{1} \Theta_{2}}{n_{1} m_{1} b s}}{c^{\prime} s-c l}
\end{aligned}
$$

where c's is the cost of trusted production for a contractual producer, $f_{3}$ is a fine deposit made by contract producers to the retailers for any product sold.

Each producer can decide whether to make a contract with a retailer. If a producer makes a contract with a retailer, the producer will become a contract producer, and vice versa. The non-contract producers sell their products to the nearest non-contract retailers. Any producer with non-trustworthy production is fined, if the producer is inspected. The contract producers sell their products to the retailers who have contracts with them. The contract producer's fine mainly derives from two aspects: inspections and investigating and tracing of its contractual retailers. It is assumed that the contract retailers can find and fine their distrusted contract producers easily. For s products sold the producers' profits are calculated as follows.

\section{Non-contract producers}

a) $p i_{1}=s\left(p_{1}-c l\right)$, when the producer is distrusted and is not inspected;

b) $p i_{2}=s\left(p_{1}-c l-f_{1}\right)$, when the producer is distrusted and fails to pass the inspection;

c) $p i_{3}=s\left(p_{1}-c s\right)$, when the producer is trusted.

\section{Contract producers}

- When the producer is distrusted and the transaction price between the producer and retailer is more than minimum protective price $\left(p_{1} \geq p r\right)$, the profit is:

a) $p i_{1}=s\left(p_{1}-c l\right)$, if the producer is not fined;

b) $p i_{2}=s\left(p_{1}-c l-f_{1}\right)$, if the producer does not pass the inspection conducted by the market regulator;

c) $p i_{3}=s\left(p_{1}-c l-f_{3}\right)$, if the producer is fined by one's own contract retailer;

d) $p i_{4}=s\left(p_{1}-c l-f_{1}-f_{3}\right)$, if the producer is fined by the market regulator and its contract retailer.

- When the producer is trusted and $\left(p_{1} \geq p r\right)$, the profit is $p i_{5}=s\left(p_{1}-c\right.$ 's $)$.

- When the producer is distrusted and $\left(p_{1}<p r\right)$, the profit is:

a) $p i_{6}=s(p r-c l)$, if the producer is not fined;

b) $p i_{7}=s\left(p r-c l-f_{1}\right)$, if the producer does not pass the inspection conducted by the market regulator;

c) $p i_{8}=s\left(p r-c l-f_{3}\right)$, if the producer is fined by its contract retailer;

d) $p i_{9}=s\left(p r-c l-f_{1}-f_{3}\right)$, if the producer is fined by the market regulator and the contract retailer.

- When the producer's production is trusted and $\left(p_{1}<p r\right)$, the profit is: $p i_{10}=s(p r-c ' s)$.
Considering the learning capacity in this model, the producers can learn and imitate from each other. If the non-contract producer's profit is less than the average profit of its neighbours, who are contract producers, it would transform into a contract producer under certain conditions. Otherwise, its type remains the same. The contract producer is in a similar situation. If the contract producer's profit is less than the average profit of its neighbours, who are non-contract producers, the contract producer would transform into a non-contract producer under certain conditions. Otherwise, the contract producer would sustain its contracts with its retailers.

Different types of producers usually coexist simultaneously in a simulation run. Prior to transformation any producer needs to take into account the financial consequences of its transformation. When the difference between the benefits and costs of the transformation exceeds threshold $(\gamma)$ the producer would change from one type to another. Otherwise, its type remains the same.

$$
\frac{\lambda\left(p i^{\prime}{ }_{i}-p i_{i}\right)}{p i^{\prime}{ }_{i}}+(1-\lambda) \rho>\gamma
$$

where $p i_{i}$ is producer(i)'s profit, $p i_{i}{ }_{i}$ is the average profit of its neighbours who are a different type of producers, parameter $\lambda$ is a weight set in the interval $(0,1)$; parameter $\rho$ is a random number $(0<\rho<1)$ and reflects fluctuations in the market.

Each producer has its own transforming threshold that implies producers' adaptability to the environment, production decision regarding its QoS and experience gained by it. The producer's transforming threshold updates with every transaction:

a) $\gamma_{t+1}=\gamma_{t}\left(1-Q o S_{t}\right)+\gamma_{t}$; if the producer is not fined;

b) $\gamma_{t+1}=\gamma_{t}\left(1-Q o S_{t}\right)$; if the producer is fined.

\subsection{Retailer-agent}

A retailer purchases products from producers in different ways, and sells them on to those downstream customers in the supply chain. The retailer's goal is to gain more profit. The attributes of a retailer are contract status (non-contracted or contracted), wealth value, and transforming threshold. The behaviour of a retailer follows the rules described below.

The retailer sells the products to the downstream of supply chain after purchase, and makes a profit that equals the total revenue minus the total cost, where revenue represents sales revenue from the market, and the cost the purchasing cost plus the fine deposit. Furthermore, the profit makes the retailer's wealth changing. We assume that each retailer sells all products, regardless of the type of producers, and that there is a uniform transaction cost $\left(p_{2}\right)$ produced when the transition between the retailer and the downstream customer is done. 
$p_{2}(t)=p_{1}(t)(1+\delta)$

where parameter $\delta$ represents the extra ratio between wholesale price and market price and is a real number from the interval $(0,1) \cdot p_{2}$ fluctuates according to $p_{1}$ on a certain scale.

When contract retailers make a contract with contract producers they provide a minimum protective price $(p r)$. When market price $p_{1}$ is higher than the protective price, the purchasing price fluctuates along with the market changes; when market price $p_{1}$ is lower than the protective price, the purchasing price becomes the protective price. The retailer's profits are calculated as given below, where bs denotes the numbers of products sold.

\section{Non-contract retailer}

- When the retailer is not inspected by the market regulator, the profit is: $r i_{1}=b s\left(p_{2}-p_{1}\right)$.

- When the retailer does not pass the inspection, the profit is: $r i_{2}=b s\left(p_{2}-p_{1}-f_{2}\right)$.

\section{Contract retailer}

- When $p_{1} \geq p r$, the profit is:

a) $r i_{1}=b s\left(p_{2}-p_{1}\right)$, if the retailer is not fined;

b) $r i_{2}=b s\left(p_{2}-p_{1}-f_{2}\right)-c i+s q f_{3}$, if the retailer is fined by the market regulator;

- When $p_{1}<p r$, the profit is:

a) $r i_{3}=b s\left(p_{2}-p r\right)$, if the retailer is not fined;

b) $r i_{4}=b s\left(p_{2}-p r-f_{2}\right)-c i+s q f_{3}$, if the retailer is fined by the market regulator.

where $q$ is the number of contract producers who are inspected by their contract retailers as a consequence of them being fined by the market regulator.

For the non-contract retailers, there is no way to find out about distrusted producers, if they fail the inspection, because they stochastically interact with some of a large number of small-scale producers on the market. Consequently, the non-contract retailers alone have to bear the fine from the market regulator. On the other hand, the contract retailers can find those distrusted producers, if they fail inspection, by several means (such as traceability system, field management and/or certification). When a contract retailer is fined, it would conduct an investigation about the distrusted producers at cost (ci), and punish those contract producers. Their punishment is a fine in the form of a deposit $\left(f_{3}\right)$ that the contract producers had paid in advance. Contract retailers build up stable interaction relationships with their producers. Moreover, their trust is strengthened with every solid transaction, resulting in their rising QoS.

In this model, the two types of retailers can learn and imitate from each other. When the non-contract retailer's profit is less than the average profit of the contract retailers, it would transform into a contract retailer under certain conditions. Otherwise, its contract status would remain the same. The contract retailer is in a similar situation and would transform into a non-contract retailer under certain conditions.

Different types of retailers usually coexist simultaneously in a simulation run. Prior to transformation any retailer needs to take into account the financial consequences of its transformation. When the difference between the benefits and costs of the transformation exceeds threshold $(v)$ the retailer would change from one type to another. Otherwise, its type remains the same.

$$
\frac{\lambda\left(r i^{\prime}{ }_{i}-r i_{i}\right)}{r i^{\prime}}+(1-\lambda) \rho>v
$$

where $r i_{i}$ is retailer(i)'s profit, and $r i_{i}{ }_{i}$ is the average profit of the retailers who are of different type, parameter $\lambda$ is a weight set in the interval $(0,1)$, parameter $\rho$ is a random number $(0<\rho<1)$ and reflects fluctuations on the market.

Each retailer has its own transforming threshold that implies retailers' adaptability to the environment, sales decision regarding its QoS and experience gained by it. The retailer's transforming threshold updates with every transaction:

a) $v_{t+1}=\mathrm{v}\left(1-Q o S_{t}\right)+v_{t}$; if the seller is not fined;

b) $v_{t+1}=v_{t}\left(1-Q o S_{t}\right)$; if the seller is fined.

\section{DISCUSSION}

The simulation model was developed and tested with NetLogo 5.3.1 [14]. Our simulation model applies to generic supply chains of partners fulfilling the supplier-customer relationship. We have focused on producers of final products and retailers of these products, who sell them to end-customers. Our goal was to study the introduction of QoS into the supply chain management. In our case QoS represents supply chain partner's trustfulness as a gradual quantitative indicator that changes (improves or deteriorates) with each transaction. The results of this oscillations are considered as a benefit or hazard when making any business deal and when considering contract relationship transitions between business partners.

With our model, we have been able to evaluate the combined impact of a number of contractual and/or non-contractual producers and retailers on the market, who are inspected by a number of market regulators with the given inspection frequencies and different fines on non-trustworthy business practices of producers and/or retailers. Hereby, we also observed the fluctuations on the market, regarding the number of contractual relations, dynamics of QoS changes and qualified rate of trustful partners' changes.

The main answers that we wished to obtain from our simulation-based DST are:

- How does the introduction of QoS impact our market?

- How do fines affect our market? 
- How does the ratio (frequency) of inspections affect our market?

- By which combination of measures can we obtain a higher qualified rate of business partners' QoS?

- By which combination of measures can we reach a situation in which the market is totally regulated (all partners are trustworthy contract partners)? The input variables of our simulation are:

- the number of producers,

- the number of retailers,

- the number of inspectors,

- the producer's fine per product,

- the retailer's fine per product,

- the fine deposit by contracted producers,

- the inspection ratio for producers,

- the inspection ratio for retailers,

- the flexibility of market $\lambda$,

- the ratio between wholesale price and market price $\delta$. There were 50 producers and 5 retailers included in our experiment. In order to achieve unified and stable conditions, $\lambda$ and $\delta$ variables have been set to 0.5 . As any producer, every retailer also has its own transforming threshold with initial values of 0.1 and 0.2 , respectively. The products are unified in production price at 1 (100\%) where the additional overhead cost of trustful production is set to $50 \%$ for non-contract producers and $40 \%$ for contract producers. Fines are considered as ratios, according to production/wholesale price and are also unified as additions to the original price. The price for investigating a distrustful contract producer, in case the retailer is fined, is set to $50 \%$ of the product price. The fine deposit by contracted producers has been set to $55 \%$ of the product price.
We have defined four characteristic scenarios for our experiment. They differ in the numbers of market regulator's inspectors, producer's fine per product, retailer's fine per product, inspection ratio for producers and inspection ratio for retailers. The final results from performing 10 replications of each individual scenario are summarised in Table 1. They present the achieved contract production ratio $(\mathrm{C} / \mathrm{P})$, maximum average QoS (QoS) and maximum qualified rate (QR) by inspections. In the sequel the individual scenarios are briefly presented. The figures with the scenario descriptions show the changes in time of the average QoS and QR rates by typical simulation runs for each scenario.

The first scenario (see Table 1) presents a free market with no contractual relationships, few market regulators, low inspection frequency and low fines for distrustful operation. From the results we can deduce that around $70 \%$ of our market has reached at least an average QoS of 58\%. Figures $1 a$ and $1 b$ show that although the QoS has reached a stable value, there are considerable deviations in the $\mathrm{QR}$, resulting from the fact that this was a free market.

The second scenario (see Table 1) presents a mixed market with many market regulators, low inspection frequency and low fines for distrustful operation. From the results we can deduce that around $70 \%$ of our market has reached at least the average QoS of $58 \%$. The probability of ending up with a fully regulated market in this case was 0.4. As opposed to Figure $1 b$ we can observe in Figure $2 b$ that the presence of contract relations somehow regulated the QR; however, although the number of market regulators was doubled, the achieved QoS was not higher.

Table 1 - Summary of simulation scenarios results

\begin{tabular}{|c|c|c|}
\hline & Input variable values & Results after 100 transactions \\
\hline 1 & $\begin{array}{l}5 \text { market regulator's inspectors, } \\
0.85 \text { producer's fine per product, } \\
1.2 \text { retailer's fine per product, } \\
0.31 \text { inspection ratio for producers, } \\
0.3 \text { inspection ratio for retailers. }\end{array}$ & $\begin{array}{l}\text { C/P: avg. 0; std. } 0 \\
\text { QoS: avg. 0.578; std. } 0.02044 \\
\text { QR: avg. 0.695; std. } 0.03837\end{array}$ \\
\hline 2 & $\begin{array}{l}10 \text { market regulator's inspectors, } \\
0.85 \text { producer's fine per product, } \\
1.2 \text { retailer's fine per product, } \\
0.31 \text { inspection ratio for producers, } \\
0.3 \text { inspection ratio for retailers. }\end{array}$ & $\begin{array}{l}\text { C/P: avg. 0.494; std. } 0.521029 \\
\text { QoS: avg. 0.5798; std. } 0.021311 \\
\text { QR: avg. } 0.7037 \text {; std. } 0.060802\end{array}$ \\
\hline 3 & $\begin{array}{l}10 \text { market regulator's inspectors, } \\
1.2 \text { producer's fine per product, } \\
2.4 \text { retailer's fine per product, } \\
0.51 \text { inspection ratio for producers, } \\
0.6 \text { inspection ratio for retailers. }\end{array}$ & $\begin{array}{l}\text { C/P: avg. 0.9; std. } 0.316228 \\
\text { QoS: avg. 0.725; std. } 0.019579 \\
\text { QR: avg. 0.887; std. } 0.023594\end{array}$ \\
\hline 4 & $\begin{array}{l}5 \text { market regulator's inspectors, } \\
0.85 \text { producer's fine per product, } \\
1.2 \text { retailer's fine per product, } \\
0.51 \text { inspection ratio for producers, } \\
0.6 \text { inspection ratio for retailers. }\end{array}$ & $\begin{array}{l}\text { C/P: avg. 0.7; std. } 0.483046 \\
\text { QoS: avg. 0.728; std. } 0.016193 \\
\text { QR: avg. 0.85; std. } 0.026247\end{array}$ \\
\hline
\end{tabular}




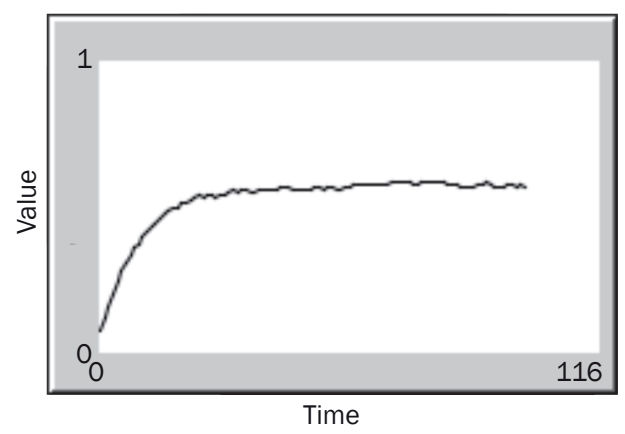

a) Average QoS

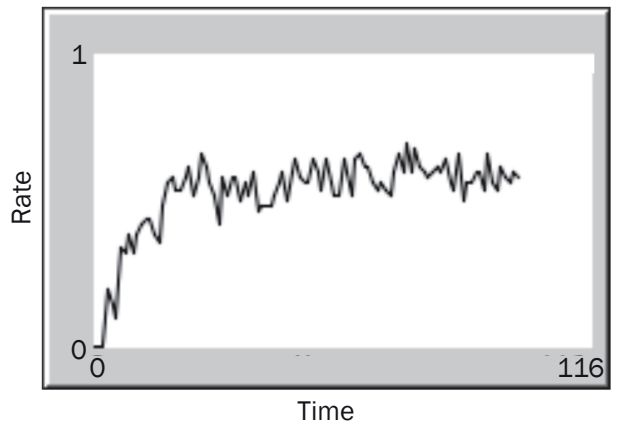

b) Qualified rate

Figure 1 - Scenario 1

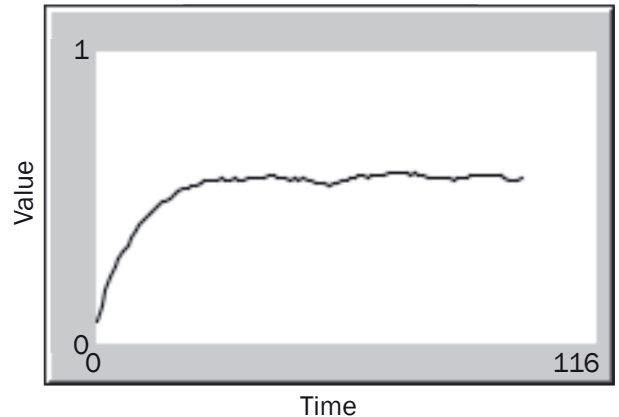

a) Average QoS

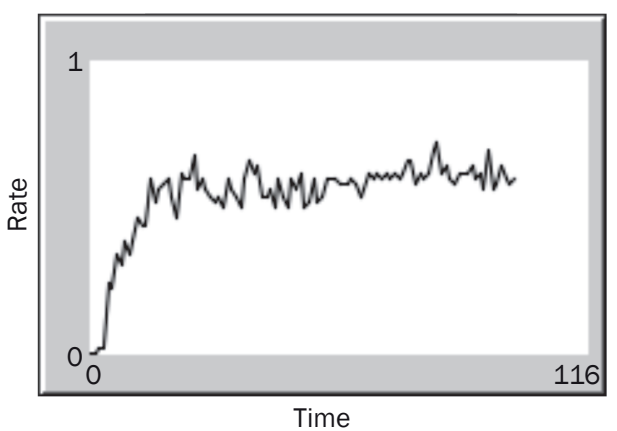

b) Qualified rate

Figure 2 - Scenario 2

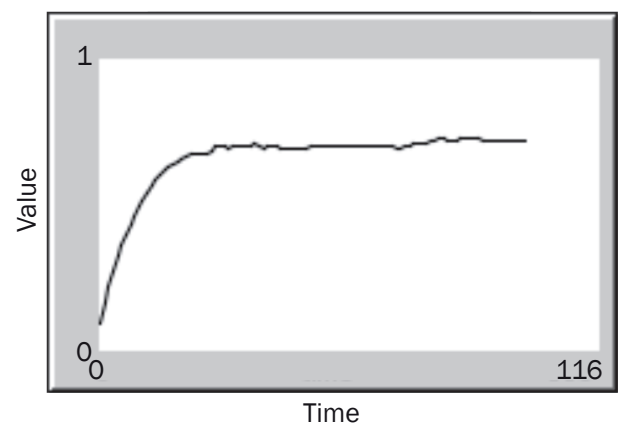

a) Average QoS

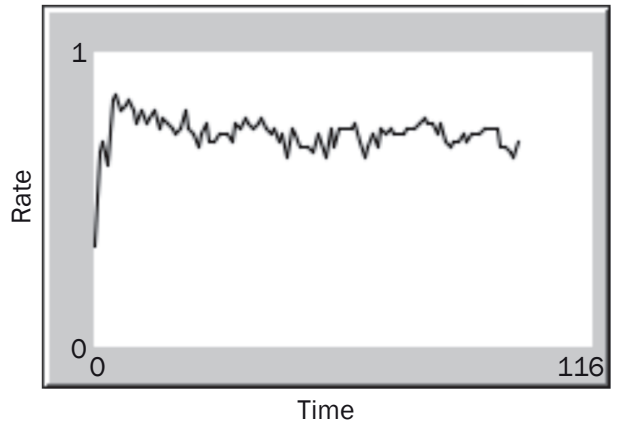

b) Qualified rate

Figure 3 - Scenario 3

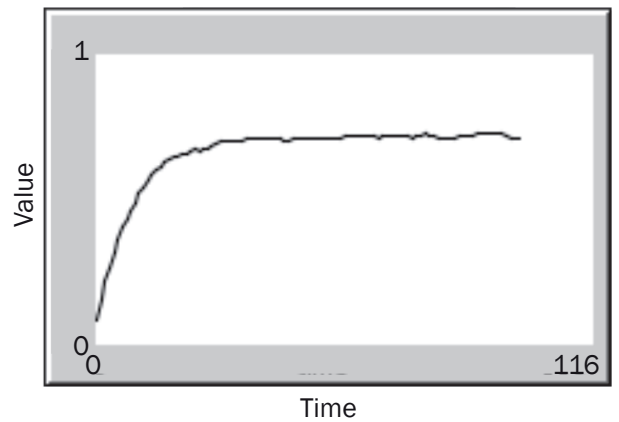

a) Average QoS

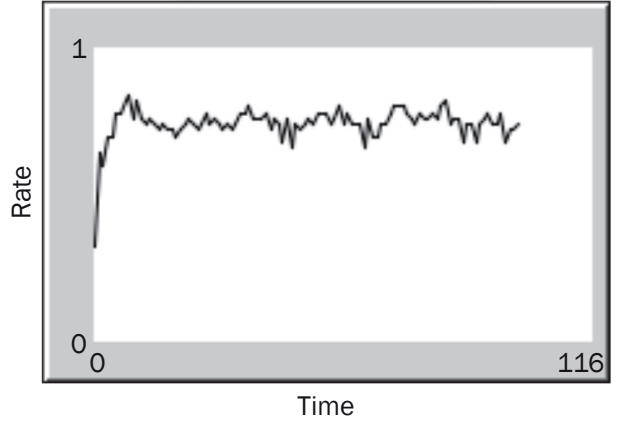

b) Qualified rate

Figure 4 - Scenario 4 
The third scenario (see Table 1) presents a mixed market with many market regulators, high inspection frequency and high fines for distrustful operation. From the results we can deduce that around $89 \%$ of our market has reached at least the average QoS of $73 \%$. The probability of ending up with a fully regulated market in this case was 0.9. In Figures $3 a$ and $3 b$ we can observe the combined effect of increasing fines and inspection ratios in relation to the previous scenario. Comparing Figures $2 a$ and $2 b$ with Figures $3 a$ and $3 b$ we can see that both the QoS and QR values in this scenario are considerably higher.

The fourth scenario (see Table 1) presents a mixed market with few market regulators, high inspection frequency and low fines for distrustful operation. From the results we can deduce that around $85 \%$ of our market has reached at least the average QoS of $73 \%$. The probability of ending up with a fully regulated market in this case was 0,7. Comparing Figures $3 a$ and $3 b$ with Figures $4 a$ and $4 b$ we can see that the effect of reducing the number of inspectors and lowering fines in this scenario did not have a significant effect on QoS and $\mathrm{QR}$ values.

QoS impact on the market is substantial. The producers as well as retailers are striving to strengthen their position in the market. With every transaction they are updating their QoS, which can lead them to a strategic decision to change their current contract status in case they discover that their profits would increase with the status change. Their decision depends on the threshold that is affected by their experience and QoS values. With every transaction resulting in their positive/negative experience their QoS is increased or decreased accordingly and also affects their future behaviour. In case their profit is above/below average profits of their neighbours and their threshold is low, their contract status may change.

The results show that in all scenarios there is an initial "warmup" period of some 30 transactions when QoS grows from its minimum to its average value. After that it does not change much. Hence, we may conclude that QoS stabilizes our market.

Qualified rate represents a share of business partners whose QoS is above average QoS. During the growth of QoS the qualified rate's oscillations are high, since the model has not yet reached a stable state and one cannot rely on the obtained $\mathrm{QR}$ results. Once QoS reaches its average value, however, the qualified rate also reaches a certain value and its oscillations are lower. The remaining oscillations are mostly associated with partners changing their contract status and hence increasing or decreasing their exposure on the market. On a fully regulated market one would expect the QoS and QR rates to be close to 1, since all partners are considered as trustful. However, since they still compete on the market this value is never reached. In the rest of the cases we can observe the expected behaviour on a free or mixed market.

Fines largely affect our market; however, they are not effective if the frequency of inspections is low, which may be associated with a low number of inspectors. According to our results, we may say that the frequencies of inspections have a bigger impact on the market than the height of fines.

We may conclude that the market is largely affected by a combination of the following three parameters: number of inspectors, fines and inspection rates. In case they are high, we are likely to end up with a fully regulated market. Otherwise, it is more likely that we end up with a mixed or even free market.

\section{CONCLUSION}

From our simulation results we can conclude that QoS is a good market regulation criterion - even on free markets the competition among non-contract partners renders an above-average overall QoS. Of course we may reach a higher QoS with contract partners in case their choice is trustfulness.

To maintain an elevated level of QoS, inspections are necessary to prevent bad business practices to prevail due to higher expected profits. On the other hand, market inspections only have a significant impact on the model, in case they are frequent. High fines for distrustful business practices alone are not sufficient market regulators.

We may sum up our conclusions with the following claim. In response to the thesis in [5] we may conclude that considering QoS in combination with the price criterion supports supply chain partners with their informed decisions and regulates their supply chains autonomously.

\section{Dr. ROMAN GUMZEJ ${ }^{1}$}

E-mail: roman.gumzej@um.si

Dr. BOJAN ROSI ${ }^{1}$

E-mail: bojan.rosi@um.s

1 Univerza v Mariboru, Fakulteta za logistiko

Mariborska cesta 7, 3000 Celje, Slovenija

\section{SIMULACIJA AGENTOV NA QOS-ORIENTIRANE OSKRBOVALNE VERIGE}

\section{POVZETEK}

Skozi adaptivnost in orientiranost na stranko bistveno izboljšamo učinkovitost upravljanja oskrbovalnih verig. Z uvajanjem odločanja na osnovi kakovosti storitve (QoS) $v$ upravljanje oskrbovalnih verig pričakujemo avtonomno in kontinuirano izboljšanje kakovosti storitve po oskrbovalni verigi navzgor in navzdol. V članku so predstavljene glavne značilnosti na kakovost storitve orientiranega upravljanja oskrbovalnih verig. Kriterij kakovosti storitve, vključen $v$ adaptivni model oskrbovalne verige, oskrbuje tržne regulatorje 
in uprave s potrebnimi informacijami in povratnimi informacijami ob sprejemanju vedno bolj informiranih odločitev. $Z$ eksperimentom, $k i$ vsebuje več tipičnih scenarijev, smo z našim simulacijskim modelom na osnovi simulacije agentov lahko empirično verificirali pričakovani vpliv odločanja na osnovi kakovosti storitve na generične adaptivne oskrbovalne verige.

\section{KLJUČNE BESEDE}

oskrbovalna veriga; adaptivnost; kakovost storitve; upravljanje; simulacija agentov;

\section{REFERENCES}

[1] Holland JH. Hidden Order: How Adaptation Builds Complexity. Addison Wesley Longman Publishing Co., Inc.; 1995.

[2] Christoper M. Logistics and Supply Chain Management. London: Prentice Hall; 2005.

[3] Rosi B, Mulej M. The dialectical network thinking - a new systems theory concerned with management. Kybernetes. 2006;35(7/8): 1165-1178.

[4] Zhang G, Shang J, Li W. Collaborative production planning of supply chain under price and demand uncertainty. European Journal of Operational Research. 2011;215(3): 590-603.

[5] Gumzej R, Gajšek B. Introducing Quality of Service Criteria into Supply Chain Management for Excellence. International Journal of Applied Logistics (IJAL). 2011;2(1): 1-16.

[6] Melo MT, Nickel S, Saldanha-da-Gama F. Facility location and supply chain management - A review. European Journal of Operational Research. 2009;169(2): 401-412.

[7] Shah N. Process industry supply chains: Advances and challenges. Computers \& Chemical Engineering. 2005;29(2005): 1225-1236.

[8] Georgiadis P, Vlachos D, lakovou E. A system dynamics modeling framework for the strategic supply chain management of food chains. Journal of Food Engineering. 2005;70(3): 351-364.

[9] Tako AA, Robinson S. The application of discrete event simulation and system dynamics in the logistics and supply chain context. Decision Support Systems. 2012;50(4): 802-815.

[10] Intihar M. System Dynamics Modeling in Supply Chain Management. In: Eichler G, Gumzej R, editors. Proceedings of the $13^{\text {th }}$ International Conference on Innovative Internet Community Systems and the International Workshop on Autonomous Systems, 2013 May/ June, Hagen, Germany. Fortschr.-Ber. VDI 10(826). Düsseldorf: VDI Verlag; 2013. p. 241-252.

[11] Angerhofer BJ, Angelides MC. System dynamics modelling in supply chain management: research review. In: Joines JA, Barton RR, Kang K, Fishwick PA, editors. 2000 Winter Simulation Conference Proceedings, 2000 December 10-13, Orlando, FL, USA. IEEE; 2000. p. 342-351.

[12] Behdani B, van Dam KH, Lukszo Z. Agent-Based Models of Supply Chains. Springer Netherlands; 2013.

[13] Xiong H, Wang P. A Simulation of Food Supply Chain (Version 1). openabm [Internet]. 2016 [cited 2017 Apr 18]; [about 9pp.]. Available from: https://www.openabm.org/model/4963/version/1/view

[14] Wilensky U. NetLogo. 1999-2016 [cited 2017 Apr 18]. Available from: Https://Ccl.Northwestern.Edu/Netlogo/Index.Shtml 